Open Access

\title{
Effect of water level fluctuations on temporal-spatial patterns of foraging activities by the wintering Hooded Crane (Grus monacha)
}

Dongmei Zhang ${ }^{1,2,3}$, Lizhi Zhou ${ }^{1,2,3^{*}}$ and Yunwei Song 1,2,3,4

\begin{abstract}
Background: The Yangtze River floodplain provides important wintering habitats for Hooded Cranes (Grus monacha) in China. Fluctuations in the water level change foraging habitat and food availability, affecting their temporal-spatial patterns of foraging activities. It is of considerable importance to investigate the effect of these fluctuations on food availability for wintering Hooded Cranes and their foraging response to these changes. Understanding their behavior patterns is beneficial in protecting the wintering crane population and restoring their wintering habitats.

Methods: A field survey of the winter behavior of cranes was carried out at Shengjin Lake from November in 2013 to April in 2014. Habitat variables, as well as the spatial distribution and behavior patterns of wintering cranes at their foraging sites during five stages of water level fluctuation were collected. Based on this data we analyzed the relationship of foraging behavior relative to water level fluctuations and habitat types.

Results: The foraging habitats used by Hooded Cranes varied at the different water level stages. As the water level decreased, the use of meadows and mudflats increased. When the water dropped to its lowest level, the use by the Hooded Crane in the mudflats reached a peak. There were statistically significant differences in time budget in the three types of habitats over the five stages of the water level. In the mudflats, the foraging behavior and maintenance behavior varied significantly with the water level, while the alert behavior showed little variation. Analysis of a generalized linear model showed that the five water level stages and three habitat types had a significant effect on foraging behavior, while the combined effect of these two variables was significant on the foraging time budget and the length of foraging activity of the Hooded Crane.

Conclusions: With the decrease in the water level, the use of mudflats by Hooded Cranes increased correspondingly. Food availability in different habitats was affected by changes in the water level. The Hooded Crane adjusted its foraging patterns and made full use of the three available types of habitat in order to acquire enough food in response to fluctuations in the water level.
\end{abstract}

Keywords: Water level fluctuations, Foraging activity, Temporal-spatial pattern, Hooded Crane, Grus monacha

\section{Background}

Seasonal variation in food availability plays an important role in population dynamics and adjustment in behavior

\footnotetext{
*Correspondence: zhoulz@ahu.edu.cn

1 School of Resources and Environmental Engineering, Anhui University,

111 Jiulong Road, Hefei 230601, China

Full list of author information is available at the end of the article
}

patterns of many avian species, especially those of waterbirds [1]. Winter is a critical period for waterbirds with its considerable effect on their annual life cycle [2]. According to the optimal foraging theory, animals choose the highest efficiency and the most advantageous patches for foraging in order to minimize their cost and maximize their income in the form of energy [3]. Affected by environmental factors of wetlands, their habitat and 
variation in food availability, waterbirds have to change their wintering habitats and behavior patterns in order to obtain sufficient energy for wintering [1,4]. For many waterbirds, fluctuations in water levels change birdperched micro-habitats [5] and directly affect the length of exposure to and availability of food in these habitats $[6,7]$. Their foraging activities are also affected by human disturbance $[8,9]$. The 'water recession' model suggests that during the dry season, lowering of water levels and surface cover will aggregate food resources in small areas, which provide extremely efficient foraging sites. Waterbirds gather in areas of rich food resources to meet their energy demand by adjusting their behavior patterns as much as possible $[1,10-12]$. Studies have shown that waterbirds have the ability to adapt to changes in water levels, food resources and environmental changes of wetlands [13, 14], but this ability is relatively limited [8].

The habitat of a dynamic wetland is a model ecosystem to observe varying behavioral responses to food limitation, because wetland-dependent species such as waterbirds must adjust to food resources that change daily [1]. Hydrological cycles and microtopography determine the spatial and temporal availability of aquatic food resources and the rate of replenishment of foraging patches after they are depleted [12]. Food abundance in this system is largely affected by the duration of marsh inundation, vegetation structure and nutrient levels. Food supply becomes available to wading birds when changes in the water level result in the aggregation of food and interacts with the vegetation to provide an open foraging habitat $[1,15]$. This changes the use of different habitats for waterbirds and limits their foraging behavior. Division of food resources leads waterbirds to take various strategies in different types of habitat [16]. In addition to biological factors, abiotic environmental factors may also strongly affect foraging and time budgets [16], e.g., temperature, wind and precipitation probably increase the need for temperature regulation to adjust foraging activities [17, $18]$.

The shallow lake wetlands along with the middle and lower Yangtze River flood plain are wetlands of international importance [19]. They contain abundant aquatic resources and are important stopover and wintering grounds for large numbers of East Asian-Australasian migratory waterbirds, including several endangered species [20]. The unique hydrological processes of the river, connecting shallow lakes, bring improved productivity and enable the accumulation of rich nutrients [21]. After the water recedes, the roots of submerged and hygrophilous plants, exposed in the riparian zone, will attract large numbers of waterbirds [22]. In recent years, these wetlands have become exposed to rapid exploitation. Seine fishery and the construction of water conservation projects have changed natural hydrological fluctuations $[23,24]$. Aquatic vegetation resources have decreased sharply, especially submerged vegetation [25]. These changes have severely disrupted the ecological process of some wetlands [22]. The habitat types and food availability have changed significantly for wintering waterbirds. Due to the degradation of the original foraging habitat, waterbirds have to turn to artificial habitats for food, such as paddy fields, resulting in changes in behavior patterns in order to adapt to the new environment $[26,27]$. The existing studies showed that the behavior of wading birds is responsive to spatial and temporal variations in the quality, quantity and availability of their food resources $[28,29]$. Foraging selection patterns can be used to assess the effects of these transient conditions.

The Hooded Crane (Grus monacha) is a large migrating wader, declared a vulnerable species by the IUCN and a national grade I protected bird in China. Its global population consists of about 11,600 birds [30]. Breeding sites are located in the eastern part of Siberia and extend to China's Lesser Khingan mountains and wintering sites for the cranes in Japan, South Korea and the middle and lower reaches of the Yangtze River in China [23, 31]. Most of the wintering population of the Hooded Crane in China assembles in the inland lakes of the Yangtze River flood plain. The food resources and their availability affect the habitat use and behavior patterns of these cranes, which have now chosen rice paddies instead of mudflats as their foraging habitat [32]. The driver of the changes in their foraging strategy merits further study. In our investigation we pay particular attention to hydrological changes and their effect on the habitat use and foraging activities of these cranes. Our aim is to shed light into: (1) the characteristics of habitat selection by the wintering Hooded Crane during different water level periods and (2) the changes in the behavior patterns of these cranes and the relationship between foraging behavior and water levels.

\section{Methods}

\section{Study area}

The study area was located at Shengjin Lake $\left(30.25^{\circ}-\right.$ $30.50^{\circ} \mathrm{N}, 116.92^{\circ}-117.25^{\circ} \mathrm{E}$ ), a shallow lake connected to the Yangtze River on the East Asian-Australasian flyway [33-35]. The region belongs to a humid subtropical monsoon climate, with an average annual temperature of $16.1^{\circ} \mathrm{C}$ and annual precipitation of $1,600 \mathrm{~mm}$. There is a clear separation between the rainy and dry seasons. The rainy season is from April to the following October, when the water level reaches $17.6 \mathrm{~m}$. The dry season usually lasts from November to March in the following year, with the water level fluctuating between 8 and $11 \mathrm{~m}$. Because of the dam at the end of the upstream Shengjin 
Lake, the water level is maintained, in the early winter, at around $11 \mathrm{~m}$ or lower till late December. In the middle of January, the water drops to its lowest level, $8.18 \mathrm{~m}$ (Fig. 1). This decrease leads to the exposure of large areas of tidal flats, providing suitable habitats for wintering waterbirds. The submerged macrophytes, such as Carex tristachya, Phalaris arundinacaea and Polygonum cripolitanumare, successively exposed in the bare substrates of the lake bottom during the water recession in autumn and winter, attract a large number of waterbirds to winter here [36, 37]. In recent years, however, rapid economic development in this wetland area has led to changes in natural hydrological fluctuation [23, 24], causing a sharp decline in aquatic vegetation [25]. The habitat availability has changed significantly, forcing wintering waterbirds to abandon their original foraging habitat that has been degraded and turn to the rice paddies to obtain a sufficient amount of food.

\section{Stages of the water level}

The water level in upstream Shengin Lake is controlled by a dam at Shengin Lake bridge and the Huangpen sluice. Depending to the way the water level rises upstream at the lake, we defined five stages of the water level during the wintering period (November 2013 to early April 2014): (a) a stable stage, from early November to late December when, due to the interception of the dam at Shengjin Lake bridge, the water level was kept at $11.04 \mathrm{~m}$; (b) a receding stage, from late December to early January: after the dam was opened, the water level dropped rapidly to $9 \mathrm{~m}$; (c) a drought stage, from early January to the end of January, when the water level

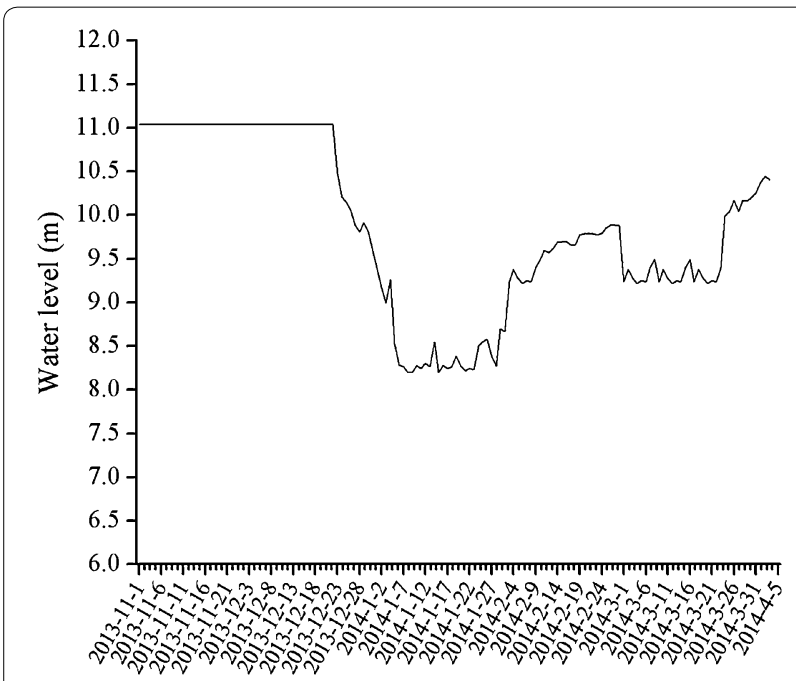

Fig. 1 Water level fluctuation upstream of Shengjin Lake during the 2013-2014 wintering period. fluctuated at a stable level between 8 and $9 \mathrm{~m}$; (d) an early recovery stage, from early February to mid-March, when the water level began to rebound, reaching 9-10 m; (e) a late recovery stage, from late March to early April, when the Hooded Cranes gradually flew away and the water level continued to rebound to $11 \mathrm{~m}$.

\section{Habitat surveys}

Based on the differences in vegetation and micro-geomorphological features, foraging habitats are distinguished into three types, i.e., mudflats, meadows and paddy fields. Within each stage of the water level, 30 quadrats of $0.5 \mathrm{~m} \times 0.5 \mathrm{~m}$ with a depth of $0.15 \mathrm{~m}$ were arranged at the foraging range of the cranes [38], located with a handheld global positioning system (GPS, eTrex 30, Garmin, China). The recorded habitat variables consisted of food types, their abundance and soil hardness $[38,39]$. In each quadrat, we collected all the tubers and roots of the aquatic vegetation, the entrails of mollusks and rice grains within $15 \mathrm{~cm}$ under the foraging site, the typical limit of foraging depth for crane species [40]. The samples were sent to the laboratory and dried at $60^{\circ} \mathrm{C}$ in an oven (YHG-9050A; Derip, Suzhou, China), for a period of $72 \mathrm{~h}$ or less, to a constant weight, which represented the dry weight $(\mathrm{g})$. We defined the ratio of the dry weight of prey resources in a quadrat $\left(0.25 \mathrm{~m}^{2}\right)$ as prey abundance $\left(\mathrm{g} \mathrm{m}^{-2}\right)$. In order to ensure the independence of data samples, the distance between two adjacent quadrats was $\geq 50 \mathrm{~m}[16]$.

\section{Bird surveys}

Each week we used a direct counting method to record the number of crane flocks, as well as the number of individual birds in each flock. We reached their feeding grounds at 7:00 in the morning of each survey day. Once we found a group of cranes, the entire visible sites were clockwise scanned using a spotter telescope (Swarovski, $30 \times 60$ ). The number of foraging cranes in each habitat, habitat type and meeting time were recorded. In order to reduce the effect of severe weather on our observations, the survey was postponed to the next day on days with strong winds, thick fogs or heavy snows [35, 40].

\section{Behavioral observations}

Field observations were carried out on sunny days from November, 2013 to April, 2014. During field work, focal sampling was conducted with binoculars $(8 \times 42)$ or a telescope $(20-60 \times 63)$ to record behavior from 07:00 to $17: 00$ [41]. At the beginning of each focal observation, date, time, location and habitat type (paddy field, meadow, mudflat) were recorded. The object of observation was usually selected as one adult in a group $(\geq 3)$. All observations were performed from a relatively remote 
location to avoid the effect of the investigators on the behavior of the crane [42]. A voice recorder (DVR-990, JNN) was used to record its behavior for 20 min unless we lost sight of our focal bird. Referring to Zhou et al. [35], the ethogram comprised the following types of behavior: foraging, alertness, maintenance, resting, locomotion and social behavior. As well, we calculated foraging success by counting the number of successful strikes during a foraging bout.

\section{Data analysis}

The relative abundance of Hooded Cranes in each habitat patch was estimated using the percentage of the number of cranes in each habitat as a proportion of the total number of cranes in all habitats during a specific period $[16,43]$. The survey results from each $20 \mathrm{~min}$ period were used as an independent sample from which we calculated the foraging frequency (changes in behavior per unit of time), length of foraging time (the total time of foraging bouts) and foraging time budget [26, 42, 44]. Foraging success was quantified by analyzing the recordings of foraging birds and budgeting their time in foraging bouts [4].

The Kruskal-Wallis $\mathrm{H}$ test and Mann-Whitney $\mathrm{U}$ test were used to test the difference of relative abundance and time budgets in three habitats at the five stages of water level. In addition, the effect of fluctuations in the water level and habitat type on foraging behavior (foraging time budget, length of time in foraging, foraging success and foraging frequency) were analyzed using a generalized linear regression model. All analyses were performed using PASW Statistics 18 (IBM Inc., 2009). A significance level of $0.05(p)$ was used for all statistical tests, with means expressed as mean \pm SE.

\section{Results}

\section{Foraging habitat use}

A total of 302 Hooded Cranes wintered at Shengjin Lake and their use of this habitat showed significant differences over the five stages of water level fluctuation (Fig. 2). The abundance of food resources in the meadow habitat was the highest, which showed significant differences over the five water level stages $\left(\chi^{2}=18.179, p=0.001\right)$. The food resources in the mudflat habitat were the least, but still, significant differences $\left(\chi^{2}=12.538, p=0.006\right)$ were found with fluctuations in the water level. In the paddy fields, the abundance of rice showed a declining trend, but the differences were not significant $\left(\chi^{2}=5.570\right.$, $p=0.234)$. As the water level receded, the number of cranes in the meadows and mudflats gradually increased. The number of cranes in the mudflats reached a peak during the drought stage. As the water level rose again, the cranes gradually reduced their use of the mudflats. At
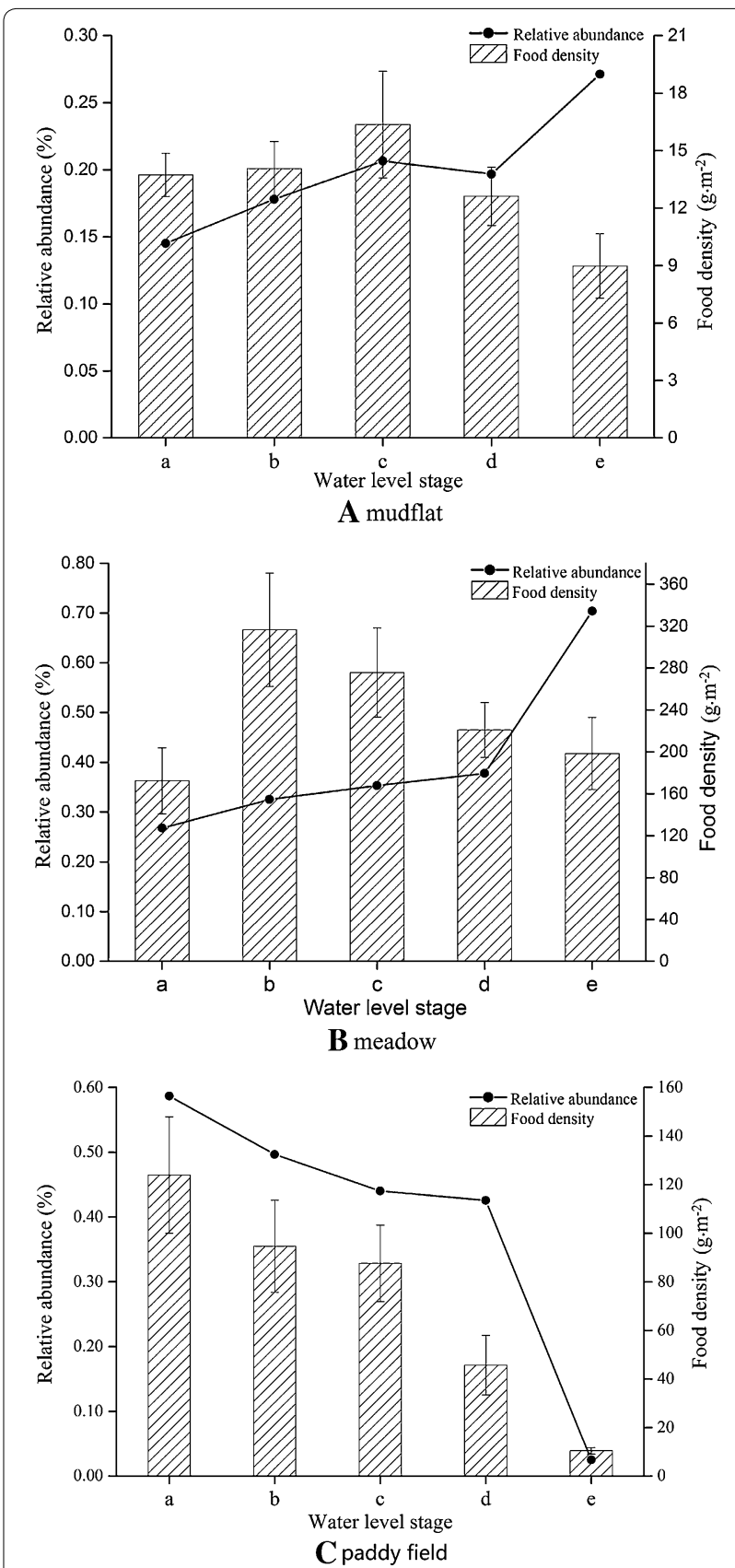

Fig. 2 Use of habitat type by Hooded Cranes under different water level features. This chart demonstrates the population dynamics of the Hooded Crane over five water level stages at three types of habitat. Changes in water level affect the spatial distribution of Hooded Cranes. The $a, b, c, d$, and e represent the five water level stages.

the late recovery stage, they abandoned the paddy fields and their use of the meadows and mudflats increased, with the meadows becoming the main foraging habitat. The number of cranes in the mudflats showed significant differences during the various stages of the water level 
$(Z=10.767, p<0.05)$. The use of meadows increased during the entire period of changes in the water level, however without any significant difference. During these stages, the use of paddy fields showed a decline.

\section{Activity time budget}

There were significant differences in activity time budget for Hooded Cranes during different stages of water level fluctuation. In mudflat, foraging behavior and maintenance were significantly different at the five stages of water level fluctuation $\left(\chi^{2}=17.328, p<0.05\right.$; $\left.\chi^{2}=14.273, p<0.01\right)$, while the alert and other behavior showed no significant difference. At the same time, the alert time in the mudflats was the highest of the three habitats (Table 1). Specifically, in the meadows the foraging behavior of the cranes increased gradually, but without any significant difference. During the entire period of water level fluctuations, the foraging time of the cranes in the paddy fields showed no significant difference $\left(\chi^{2}=3.391, p>0.05\right)$,but was higher than in the mudflats. The alert time in the paddy fields decreased, with a slightly increase during the early recovery stage but again showed no significant difference $\left(\chi^{2}=6.485, p>0.05\right)$.

\section{Temporal-spatial changes in foraging activities}

In the three habitat types, only the foraging behavior in the mudflats showed significant differences during the various water level stages. The foraging strategies of the cranes were considerably affected by fluctuations in the water level, changing the length of time in foraging, foraging frequency, foraging time budget and especially their foraging success (Table 2). The type of habitat showed an extremely marked effect on their foraging time budget and foraging success, but less on the length spent on foraging. Moreover, the combined action of habitat type and water level fluctuation had a significant effect on foraging time, but did not affect the foraging frequency nor foraging success.

\section{Discussion}

\section{Effect of water level fluctuation on foraging habitat use}

There are many factors that can affect the habitat selection of waterbirds. Consequently, understanding the role of fluctuation in water levels in wetlands has become even more crucial, especially with current concerns about global climate change [38, 45, 46]. Seasonality and the extent of these fluctuations affect habitat features such as water depth, food availability and degree

Table 1 Activity time budgets of Hooded Cranes over five water level stages at Shengjin Lake

\begin{tabular}{|c|c|c|c|c|c|c|c|c|}
\hline \multirow[t]{2}{*}{ Habitat type } & \multirow[t]{2}{*}{ Behavior } & \multicolumn{5}{|c|}{ Activity time budgets at various water level stages (\%) } & \multicolumn{2}{|l|}{ Statistical test } \\
\hline & & a & b & c & d & e & Chi Square value $\left(\chi^{2}\right)$ & $p$ \\
\hline \multirow[t]{6}{*}{ Mudflat } & Foraging & $0.47 \pm 0.06$ & $0.59 \pm 0.02$ & $0.50 \pm 0.05$ & $0.35 \pm 0.06$ & $0.29 \pm 0.07$ & 17.328 & $0.002^{* *}$ \\
\hline & Alert & $0.36 \pm 0.06$ & $0.23 \pm 0.03$ & $0.25 \pm 0.03$ & $0.25 \pm 0.03$ & $0.34 \pm 0.05$ & 7.36 & 0.118 \\
\hline & Maintenance & $0.12 \pm 0.03$ & $0.08 \pm 0.02$ & $0.16 \pm 0.03$ & $0.26 \pm 0.04$ & $0.27 \pm 0.05$ & 14.273 & $0.006^{* *}$ \\
\hline & Social behavior & $0.00 \pm 0.00$ & $0.01 \pm 0.01$ & $0.01 \pm 0.01$ & $0.00 \pm 0.00$ & $0.00 \pm 0.00$ & 5.153 & 0.272 \\
\hline & Locomotion & $0.04 \pm 0.01$ & $0.08 \pm 0.02$ & $0.06 \pm 0.02$ & $0.13 \pm 0.03$ & $0.11 \pm 0.04$ & 5.407 & 0.248 \\
\hline & Resting & $0.01 \pm 0.01$ & $0.00 \pm 0.00$ & $0.02 \pm 0.01$ & $0.01 \pm 0.01$ & $0.00 \pm 0.00$ & 5.626 & 0.229 \\
\hline \multirow[t]{6}{*}{ Meadow } & Foraging & $0.60 \pm 0.09$ & $0.70 \pm 0.06$ & $0.74 \pm 0.02$ & $0.79 \pm 0.04$ & $0.79 \pm 0.04$ & 5.508 & 0.230 \\
\hline & Alert & $0.21 \pm 0.05$ & $0.15 \pm 0.03$ & $0.18 \pm 0.02$ & $0.15 \pm 0.02$ & $0.16 \pm 0.03$ & 2.697 & 0.610 \\
\hline & Maintenance & $0.11 \pm 0.05$ & $0.12 \pm 0.04$ & $0.05 \pm 0.01$ & $0.04 \pm 0.02$ & $0.03 \pm 0.01$ & 2.731 & 0.604 \\
\hline & Social behavior & $0.00 \pm 0.00$ & $0.00 \pm 0.00$ & $0.01 \pm 0.01$ & $0.00 \pm 0.00$ & $0.00 \pm 0.00$ & 2.750 & 0.600 \\
\hline & Locomotion & $0.04 \pm 0.02$ & $0.03 \pm 0.01$ & $0.02 \pm 0.01$ & $0.02 \pm 0.01$ & $0.02 \pm 0.01$ & 2.054 & 0.726 \\
\hline & Resting & $0.04 \pm 0.03$ & $0.00 \pm 0.00$ & $0.00 \pm 0.00$ & $0.00 \pm 0.00$ & $0.00 \pm 0.00$ & 7.346 & 0.119 \\
\hline \multirow[t]{6}{*}{ Paddy field } & Foraging & $0.63 \pm 0.06$ & $0.71 \pm 0.05$ & $0.79 \pm 0.03$ & $0.73 \pm 0.04$ & - & 3.391 & 0.355 \\
\hline & Alert & $0.28 \pm 0.04$ & $0.22 \pm 0.04$ & $0.13 \pm 0.02$ & $0.20 \pm 0.03$ & - & 6.485 & 0.090 \\
\hline & Maintenance & $0.06 \pm 0.03$ & $0.07 \pm 0.03$ & $0.06 \pm 0.02$ & $0.05 \pm 0.01$ & - & 7.670 & 0.053 \\
\hline & Social behavior & $0.03 \pm 0.01$ & $0.00 \pm 0.00$ & $0.01 \pm 0.00$ & $0.00 \pm 0.00$ & - & 14.895 & $0.002^{* *}$ \\
\hline & Locomotion & $0.03 \pm 0.01$ & $0.01 \pm 0.00$ & $0.01 \pm 0.00$ & $0.01 \pm 0.00$ & - & 14.837 & $0.002^{* *}$ \\
\hline & Resting & $0.00 \pm 0.00$ & $0.00 \pm 0.00$ & $0.00 \pm 0.00$ & $0.00 \pm 0.00$ & - & 2.303 & 0.512 \\
\hline
\end{tabular}

Samples: (a) Stable stage: mudflat $n=21$; meadow $n=25$; paddy field $n=32$; (b) Falling stage: mudflat $n=25$; meadow $n=26$; paddy field $n=35$; (c) Drought stage: mudflat $n=22$; meadow $n=30$; paddy field $n=31$; (d) Early recovery stage: mudflat $n=25$; meadow $n=26$; paddy field $\mathrm{n}=22$; (e) Late recovery stage: mudflat $n=27$; meadow $n=31$; paddy field $n=0$.

${ }^{*} p<0.05 ;{ }^{* *} p<0.01 ;{ }^{* * *} p<0.001 ; n=$ the sample size.

- denotes that the cranes did not utilize this habitat. 
Table 2 Variation in foraging behavior of Hooded Cranes in response to changes in the water levels and habitat types $(n=378)$

\begin{tabular}{|c|c|c|c|c|c|c|c|c|}
\hline \multirow[t]{2}{*}{ Variables } & \multicolumn{2}{|c|}{ Length of foraging } & \multicolumn{2}{|c|}{ Foraging frequency } & \multicolumn{2}{|c|}{ Foraging time budget } & \multicolumn{2}{|c|}{ Foraging success } \\
\hline & $F$ & $P$ & $F$ & $P$ & $F$ & $P$ & $F$ & $P$ \\
\hline Stage & 3.521 & 0.008 & 2.426 & 0.048 & 3.467 & 0.009 & 8.773 & 0.000 \\
\hline Habitat & 2.195 & 0.113 & 3.048 & 0.049 & 36.987 & 0.000 & 28.953 & 0.000 \\
\hline Stage $\times$ habitat & 3.178 & 0.003 & 1.974 & 0.058 & 4.390 & 0.000 & 1.742 & 0.098 \\
\hline
\end{tabular}

of isolation from human disturbance, creating a mosaic that changes over time and space [47-49]. A mudflat is a habitat where food availability changes considerably with the water level. When the water level declines, the area of mudflats becomes larger, especially in the shallow lake wetlands along with the floodplains of the middle and lower Yangtze River. On the other hand, when the water level rises, waterbirds will be faced with a reduction of habitat area and food availability, as well as with an increase in human interference [50]. According to the 'water recession' model, lowering water levels and receding surface cover tend to concentrate food in small areas which provide extremely efficient foraging sites [11], thereby meeting the food demands of more waterbirds. Recently, aquatic vegetation resources in Shengjin Lake decreased sharply, especially the submerged vegetation [25]. Although more mudflats will be exposed with a falling water level, the available food resources for the cranes have not increased significantly, thus failing to provide an adequate food supply. All the same, the number of Hooded Cranes wintering in the mudflats has increased considerably. Although the mudflats failed to provide sufficient food, the Hooded Crane has not yet given up this optimal foraging habitat. This is mainly because human disturbance is lower in the mudflats and declining water levels provide for a wider range of habitats. The strategy of seasonal movement allows cranes to use the resources available over all of the wetlands during the course of the wintering period [51].

\section{Effect of water level fluctuation on activity time budget}

The foraging strategy of predators often conforms to the principle of optimal foraging theory [52-54]. The daily food requirements of birds depend on time budget, activity level, assimilation efficiency and the amount of energy contained in food [6]. Time-activity budgets of waterbirds in the winter could provide data on differential habitat use, evaluate responses of waterbirds to environmental conditions, make inferences about energy budgets and compare populations at different stages during the winter $[55,56]$. To study the behavioral patterns and time budgets for understanding the changes of habitat use, energy requirement and seasonal variation is of great importance [42].

Wetland degradation leads to changes in the optimal wintering habitat of Hooded Cranes and interferes with their behavior pattern [57]. Waterbirds can respond in their behavior to spatial and temporal variations in the quality, quantity and availability of food resources [29]. A habitat use study of the Hooded Crane in Chongming Dongtan suggests that a mudflat is its optimal foraging habitat [58]. In our present study, we found that the area of mudflats exposed in Shengjin Lake increased when the water level decreased. During this process, foraging time did not increase much, whereas maintenance behavior clearly increased. This suggests that the Hooded Crane did not give up its original habitat, but shifted its foraging strategy to adapt to this relatively degraded habitat. The degradation of natural wetlands has forced the cranes to shift their foraging habitats to artificial wetlands, thus leading to a reallocation of time budgets in order to adapt to the new habitat $[26,27]$. Paddy field and meadow habitats with stronger human disturbance were originally unsuitable habitat types, but now these have become the main foraging habitats of the Hooded Crane in the lakes of the Yangtze River floodplain in Anhui Province. Simultaneously, mudflats have become the main stopover for cranes foraging [32]. As water level rose again, food resources could not be obtained and waterbirds opted for other habitats for foraging [7]. The Hooded Cranes turned to meadows, increasing the foraging time to get sufficient energy. Accordingly, changing the behavior pattern is a strategy to adapt in the face of the collapse of food resources. Their behavior of changing the types of foraging habitat is consistent with optimal foraging theory.

\section{Effect of water levels on foraging frequency and success rate}

Hydrological cycles and micro-topography determine the spatial and temporal availability of aquatic food and the rate of replenishment of foraging patches after they are depleted [1]. Predilection of habitat type and water depth and the shift of diet for waterbirds all can be caused by 
the availability of food resources [1]. Foraging frequency, length of time spent on foraging and foraging success can reflect the effect of water level fluctuations and the foraging efficiency of waterbirds [56]. The stages of the water level have significantly impacted the foraging behavior of the Hooded Crane. Fluctuating water levels change the area of the exposed habitats as well as the soil hardness, which causes changes in food availability [59]. Accordingly, cranes adjust their foraging time budget to different water levels, responding to the changes in food resource abundance and availability and thus gain a greater energy intake with relatively less effort [60]. The foraging frequency of cranes was affected by the various types of food and interference in different habitats. Human disturbance is higher in paddy fields, but food resources are richer than in other habitats. This allowed the cranes the highest foraging frequency and foraging success rate. They foraged here during their foraging peak, then flew back to the habitats with lower human disturbance such as the mudflats. The behavior rhythm of cranes has clear spatial heterogeneity [61]. The foraging behavior of our cranes showed temporal and spatial differences, caused by a combination of changes in the water level and habitat type. They did not forage in a single habitat, but allocated their foraging times to different habitats. This is probably because the type and density of food resources in the various habitats are not the same. The Hooded Cranes avoid excessive use of a single type of habitat and balance their nutritional intake by foraging a variety of food resources $[16,62]$. Therefore, in order to gain higher foraging yield, the cranes adapted to the changes in food resource availability caused by water levels and habitat type by altering their foraging strategy.

\section{Importance of water management for crane conservation}

The normal water level fluctuations of lake wetlands play a key role in maintaining waterbird communities [63]. Understanding the impact of changing water levels on waterbirds is of great importance for the restoration of their wintering habitats and for the protection of bird populations [64]. For the last years, the over-exploitation of wetland has led to a decline in wetland areas, thus reducing the habitat available to cranes [65]. Water conservation projects are implemented for the sake of human demands such as control of the water level, shipping and aquaculture. But these projects often cause changes in the natural hydrology rhythm. Long periods of high water levels will cause a reduction in food resources on mudflats, while rapidly decreasing water levels will accelerate the drying of mudflats. Both conditions can reduce the availability of food resource on mudflats and affect the population of wintering cranes. It is critical to enhance the lake management and ecological restoration.
The dam built under the Shengjin Lake bridge should be opened as early as possible to prevent the upstream of Shengjin Lake remaining at high water levels all the time. In this way, the tidal flats can be exposed, providing sufficient habitats for cranes and other waterbirds. More research is needed for determining the response patterns among water levels, habitats and wintering cranes. It is beneficial for wetlands and waterbirds to conduct longterm effective monitoring of water levels, waterbirds and other ecological characteristics.

\section{Conclusions}

Our study has shown that with the decrease of water levels, the use of mudflats by Hooded Cranes increased correspondingly. Food availability in the various habitats was affected by fluctuations in the water level. The Hooded Crane reacted by adjusting its behavior patterns and made full use of the three types of habitat in order to obtain a sufficient amount of food in response to the fluctuations in the water level.

\section{Authors' contributions}

DZ and LZ conceived and designed the experiments. DZ performed the experiments, DZ and LZ analyzed the data. LZ contributed the reagents/ materials/analysis tools and DZ and LZ wrote the paper. LZ liaised with nature reserve authorities and obtained province guidance and permission for the field work. YS participated in the field work. All authors read and approved the final manuscript.

\section{Author details}

${ }^{1}$ School of Resources and Environmental Engineering, Anhui University, 111 Jiulong Road, Hefei 230601, China. ${ }^{2}$ Institute of Biodiversity and Wetland Ecology, Anhui University, 111 Jiulong Road, Hefei 230601, China. ${ }^{3}$ Anhui Biodiversity Information Center, 111 Jiulong Road, Hefei 230601, China. ${ }^{4}$ Shengjin Lake National Nature Reserve of Anhui Province, Chizhou 247200, China.

\section{Acknowledgements}

The work was supported by the National Natural Science Foundation of China (Grant no. 31172117, 31472020) and the Graduate Student Innovation Research Projects of Anhui University (YQH100269). We express appreciation to Dr. Chunlin Li for his helpful comments and suggestions on our study and the staff of the Shengjin Lake National N. R. for their helps in the field work.

Compliance with ethical guidelines

\section{Competing interests}

The authors declare that they have no competing interests.

Received: 15 February 2015 Accepted: 22 July 2015

Published online: 05 August 2015

\section{References}

1. Beerens JM, Gawlik DE, Herring G, Cook MI (2011) Dynamic habitat selection by two wading bird speices with divergent foraging strategies in a seasonally fluctuation wetland. Auk 128(4):651-662

2. Marra PP, Hobson KA, Holmes RT (1998) Linking winter and summer events in a migratory bird by using stable carbon isotopes. Science 282:1884-1886

3. May R, Mclean A (2010) Theoretical ecology. Oxford University Press, Oxford

4. Kuwae T, Miyoshi E, Sassa S, Watabe Y (2010) Foraging mode shift in varying environmental conditions by dunlin Calidris alpina. Mar Ecol Prog Ser 406:281-289 
5. Farago S, Hangya K (2012) Effects of water level on waterbird abundance and diversity along the middle section of the Danube River. Hydrobiologia 697(1):15-21

6. Kushlan JA (1978) Nonrigorous foraging by robbing egrets. Ecology 59(4):649-653

7. Maheswaran G, Rahmani AR (2001) Effects of water level changes and wading bird abundance on the foraging behavior of black necked storks Ephippiorhynchus asiaticus in Dudwa National Park, India. J Biosci 26(3):373-382

8. Lantz SM, Gawlik DE, Cook MI (2010) The effects of water depth and submerged aquatic vegetation on the selection of foraging habitat and foraging success of wading birds. Condor 112(3):460-469

9. Master TL, Lesier JK, Bennett KA (2005) Patch selection by Snowy Egrets. Colon Waterbird 28:220-224

10. Lewis TL, Esler D, Boyd WS (2008) Foraging behavior of Surf Scoters (Melanitta perspicillata) and White-Winged Scoters ( $M$. fusca) in relation to clam density: inferring food availability and habitat quality. Auk 125(1):149-157

11. Loftus WF, Eklund AM (1994) Long-term dynamics of an Everglades smallfish assemblage. In: Davis SM, Ogden JC (eds) Everglades: the ecosystem and its restoration. CRC Press, Boca Raton, FL, pp 461-483

12. Russell GJ, Bass OL Jr, Pimm SL (2002) The effect of hydrological patterns and breeding-season flooding on the numbers and distribution of wading birds in Everglades National Park. Anim Conserv 5:185-199

13. Baschuk MS, Koper N, Wrubleski DA, Goldsborough G (2012) Effects of water depth, cover and food resources on habitat use of marsh birds and waterfowl in boreal wetlands of Manitoba, Canada. Waterbirds 35(1):44-55

14. Holm TE, Clausen P (2006) Effects of water level management on autumn staging waterbird and macrophyte diversity in three Danish coastal lagoons. Biodiv Conserv 15:4399-4423

15. Bancroft GT, Gawlik DE, Rutchey K (2002) Distribution of wading birds relative to vegetation and water depths in the northern Everglades of Florida, USA. Waterbirds 25:265-277

16. Jing K, Ma ZJ, Li B, Li JH, Chen JK (2007) Foraging strategies involved in habitat use of shorebirds at the intertidal area of Chongming Dongtan, China. Ecol Res 22:559-570

17. Beauchamp G (2006) Spatial, temporal and weather factors influencing the foraging behavior of migrating Semipalmated Sandpipers. Waterbirds 29(2):221-225

18. Pienkowski MW (1983) Surface activity of some intertidal invertebrates in relation to temperature and the foraging behaviour of their shorebird predators. Mar Ecol Prog Ser 11:141-150

19. Zhao F, Zhou L, Xu W (2013) Habitat utilization and resource partitioning of wintering Hooded Cranes and three goose species at Shengjin Lake. Chin Birds 4:281-290

20. Cao L, Barter M, Zhao MJ, Meng HX, Zhang Y (2011) A systematic scheme for monitoring waterbird populations at Shengjin Lake, China: methodology and preliminary results. Chin Birds 2:1-17

21. Liu ZY, Xu WB, Wang QS, Shi KC, Xu JS, Yu GQ (2001) Environmental carrying capacity for over wintering Hooded Cranes in Shengjin Lake. Resour Envir Yangtze Basin 10(5):454-459

22. Cao L, Fox AD (2009) Birds and people both depend on China's wetlands. Nature 460:173

23. BirdLife International (2001) Threatened birds of Asia: the BirdLife international red data book. BirdLife International, Cambridge, pp 1174-1179

24. Yang GS, Ma GH, Zhang L, Jiang JH, Yao SC, Zhang M et al (2010) Lake status, major problems and protection strategy in China. J Lake Sc 22(6):799-810

25. Fox AD, Cao L, Zhang Y, Barter M, Zhao MJ, Meng FJ et al (2011) Declines in the tuber-feeding waterbird guild at Shengjin Lake National Nature Reserve, China-a barometer of submerged macrophyte collapse. Aquatic Conserv Mar Freshw Ecosyst 21:82-91

26. Li ZQ, Wang Z, Ge C (2013) Time budgets of wintering Red-Crowned Cranes: effects of habitat, age and family size. Wetlands 33:227-232

27. Wood C, Qiao Y, Li P, Ding P, Lu BZ, Xi YM (2010) Implications of rice agriculture for wild birds in China. Waterbirds 33(Sp1):30-43

28. Aviles JM (2003) Time budget and habitat use of the Common Crane wintering in dehesas of southwestern Spain. Can J Zool 81:1233-1238

29. Erwin RM (1983) Feeding habitats of nesting wading birds: spatial use and social influences. Auk 100:960-970
30. BirdLife International (2012) Grus monacha. The IUCN red list of threatened species. Version 2015.2. http://www.iucnredlist.org. Accessed 2 Aug 2015

31. Jiao SW, Guo YM, Falk H, Lei GC (2014) Nest-site selection analysis of Hooded Crane (Grus monacha) in Northeastern China based on a multivariate ensemble model. Zoolog Sci 31:430-437

32. Luo ZJ (2012) Habitat selection of Hooded Crane (Grus monacha) wintering at the lakes of Yangtze River Floodplain in Anhui Province. Master's Thesis. Anhui University

33. Fox AD, Hearn RD, Cao L (2008) Preliminary observations of diurnal feeding patterns of swan geese (Anser cygnoides) using two different habitats at Shengjin Lake, Anhui Province, China. Wildfowl 58:20-30

34. James $\mathrm{H}$ (2000) Migratory stopover and wintering locations in eastern China used by White-naped Cranes Grus vipio and Hooded Cranes G. monacha as determined by satellite tracking. Forktail 16:93-99

35. Zhou B, Zhou LZ, Chen JY, Cheng YQ, Xu WB (2010) Diurnal time-activity budgets of wintering Hooded cranes (Grus monacha) in Shengjin Lake, China. Waterbirds 33(1):110-115

36. Xu LL, Xu WB, Sun QY, Zhou ZZ, Shen J, Zhao XX (2008) Flora and vegetation in Shengjin Lake. J Wuhan Botan Res 27(3):264-270

37. Yang XL (2011) Research on the numbers, distribution, feeding behavior and diet of Great White Fronted Geese at Shengjin Lake, the national natural reserves in Anhui Province. Master's Thesis. University of Science and Technology of China

38. Ma ZJ, Li B, Jing K, Zhao B, Tang SM, Chen JK (2003) Effects of tidewater on the feeding ecology of Hooded Crane (Grus monacha) and conservation of their wintering habitats at ChongmingDongtan, China. Ecol Res 18:321-329

39. Zhao C, Li YH, Hu J, Yao G, He Q, Li HY et al (2012) Feeding sites selection of long-billed plover in winter at the middle reaches of Jialing River. Sichuan J Zool 31(1):22-26

40. Jia YF (2013) Impact of water level fluctuation on Siberian Crane and other wintering waterbirds in Poyang Lake. PhD Thesis. Beijing Forestry University, Beijing

41. Lamoot I (2004) Foraging behaviour and habitat use of large herbivores in a coastal dune landscape. PhD Thesis. Universiteit Gent, Gent

42. Azevedo CS, Ferraz JB, Tinoco HP, Young RJ, Rodrigues M (2010) Timeactivity budget of greater rheas (Rhea Americana, Aves) on a humandisturbed area: the role of habitat, time of the day, season and group size. Acta Ethol 13:109-117

43. Gyimesi A, Franken MS, Feige N, Nolet BA (2012) Human disturbance of Bewick's Swans is reflected in giving-up net energy intake rate, but not in giving-up food density. Ibis 154(4):781-790

44. Lafever KE (2006) Spatial and temporal winter territory use and behaviora responses of Whooping Cranes to human activities. Doctoral Dissertation. Texas A\&M University

45. Coops H, Beklioglu M, Crisman TL (2003) The role of water-level fluctuations in shallow lake ecosystems-workshop conclusions. Hydrobiologia 506-509:23-27

46. Wantzen KM, Rothhaupt KO, Mortl M, Cantonati M, Toth LG, Fischer P (2008) Ecological effects of water-level fluctuations in lakes: an urgent issue. Hydrobiologia 613:1-4

47. Bolduc F, Afton AD (2008) Monitoring waterbird abundance in wetlands: the importance of controlling results for variation in water depth. Ecol Model 216(3):402-408

48. Dimalexis A, Pyrovetsi M (1997) Effect of water level fluctuations on wading bird foraging habitat use at an Irrigatio Reservoir, Lake Kerkini, Greece. Colon Waterbird 20(2):244-252

49. Rajpar MN, Zakaria M (2011) Effects of water level fluctuation on waterbirds distribution and aquatic vegetation composition at natura wetland reserve, Peninsular Malaysia. ISRN Ecol 2011:1-13

50. Li YK, Shan JH, Ma JZ, Miu LJ, Li J, Yuan FK et al (2014) The effects of climate and water level fluctuation on the wintering population of Oriental White Stork. Chin J Ecol 33(4):1061-1067

51. Kushlan JA (1986) Responses of wading birds to seasonally fluctuating water levels: strategies and their limits. Colon Waterbird 2(9):155-162

52. Krebs JR (1978) Optimal foraging: decision rules for predators. In: Krebs JR, Davies NB (eds) Behavioural ecology: an evolutionary approach. Blackwell, Oxford, pp 23-63

53. Macarthur R, Recher H, Cody M (1966) On the relation between habitat selection and species diversity. Amer Natur 100:319-332 
54. Stephens DW (1986) Foraging theory. Princeton University Press, Princeton

55. Paulus SL (1988) Time-activity budgets of nonbreeding Anatidae: a review. In: Weller MW (ed) Waterfowl in winter. University of Minnesota Press, Minneapolis, pp 135-152

56. Woodin MC, Michot TC (2006) Foraging behavior of redheads (Aythya americana) wintering in Texas and Louisiana. Hydrobiologia 567:129-14

57. Lee SD, Jabtonski PG, Higuchi H (2007) Winter foraging of threatened cranes in the Demilitarized Zone of Korea: behavioral evidence for the conservation importance of unplowed rice fields. Biol Conserv 138:286-289

58. Jing K, Tang SM, Chen JK, Ma ZJ (2002) Primary research on the characteristics of feeding sites of Grus monacha in the east tide flat of Chongming. Zool Res 23(1):84-88

59. Riis T, Hawes I (2002) Relationships between water level fluctuations and vegetation diversity in shallow water of New Zealand lakes. Aquat Bot 74:133-148
60. Zheng M (2014) The effects of food resource dynamics on foraging behaviors of wintering Hooded Cranes (Grus monacha) over spatiotemporal scales. Master's Thesis. Anhui University

61. Aborn DA (2010) Behavior and habitat use of Greater Sandhill Cranes wintering in east Tennessee. Crane Workshop 11:9-14

62. Slobodkin LB (1974) Prudent predation does not require group selection. Amer Natur 108:665-678

63. Coops H, Hosper SH (2002) Water-level management as a tool for the restoration of Shallow Lake in the Netherlands. Lake Reserv Manag 18(4):293-298

64. Gawlik DE (2006) The role of wild life science in wetland ecosystem restoration: lessons from the Everglades. Ecol Eng 26:70-83

65. Zhu WZ, Zhou LZ (2010) Biodoversity and conservation in Anqing floodplain wetlands. Hefei University of Technology Press, Hefei
Submit your next manuscript to BioMed Central and take full advantage of:

- Convenient online submission

- Thorough peer review

- No space constraints or color figure charges

- Immediate publication on acceptance

- Inclusion in PubMed, CAS, Scopus and Google Scholar

- Research which is freely available for redistribution

Submit your manuscript at www.biomedcentral.com/submit 